RETORIKA: Jurnal Ilmu Bahasa, Vol. 1, No. 2 Oktober 2015, 298-308

Available Online at http://ejournal.warmadewa.ac.id/index.php/jret

\title{
FITUR LINGUISTIK DAN NON-LINGUISTIK PENGGUNAAN BAHA- SA SMS PADA SISWA SMPN 4 MATARAM DAN IMPLIKASINYA TER- HADAP PEMBELAJARAN BAHASA INDONESIA DI SEKOLAH
}

\author{
Endang Sriningsih \\ Universitas Mataram \\ ningsihendang68@gmail.com
}

\begin{abstract}
Abstrak
Isu sentral yang dikaji dalam penelitian ini adalah 1) bagaimanakah fitur linguistik dan non-linguistik yang digunakan siswa dalam berbahasa $S M S$ dan 2) bagaimanakah implikasi fitur linguistik dan nonlinguistik penggunaan bahasa $S M S$ pada siswa kelas VIII 10 SMPN 4 Mataram tahun pelajaran 2014/ 2015 terhadap pembelajaran bahasa Indonesia di sekolah? Data yang dipergunakan untuk menjawab tiga persoalan tersebut diperoleh dari para siswa berupa fitur linguistik dan non-linguistik penggunaan bahasa SMS. Teknik pengumpulan data dengan cara: memotret (Capture atau Screenshot) dari $H P$ mereka, observasi, mencatat kejadian di lapangan, kuesioner, dan wawancara. Seluruh data yang ada diidentifikasi, dikodifikasi, diklasifikasi, dan dianalisis. Data dianalisis berdasarkan bentuk, fungsi, makna, kontak sosial, dan implikasinya terhadap pembelajaran di sekolah. Hasil analisis menunjukkan bahwa fitur bahasa SMS para siswa berupa pesan verbal, yang terdiri dari fonem, morfem, leksikon, frasa, dan kalimat dan pesan non-verbal berupa emoticon (tanda rasa).
\end{abstract}

Kata kunci: fitur, linguistik, dan SMS

\begin{abstract}
Phenomena that arise in the use of SMS language students formulated in three issues. 1) How the linguistic and non-linguistic features used by students in SMS language? and 2) How are the implications of linguistic features and non-linguistic use SMS language in class VIII 10 SMPN 4 Mataram school year 2014/2015 against the Indonesian language learning in school? The data used to address three issues were obtained from students in the form of linguistic features and non-linguistic use SMS language. Data collection techniques by means of: photographing (Capture or Screenshot) from their HP, observation, noting the incident in the field, questionnaires, and interviews. All data that is identified, codified, classified, and analyzed. Data were analyzed based on form, function, meaning, social contacts, and their implications for learning in school. Results of analysis shows that features SMS language students in the form of verbal messages, which consist of phoneme, morpheme, lexicon, phrases, and sentences and non-verbal messages such as emoticons (sign of). This study recommends further research in order to dig deeper, related to the phenomenon of the use of SMS language by the students. This study examines are not yet research about the use of SMS language by students against older adults.
\end{abstract}

Keywords: features, linguistic, and SMS

\section{PENDAHULUAN}

Manusia memiliki kebutuhan berinteraksi dan berkomunikasi. Untuk melancarkan kebutuhan tersebut, diperlukan teknologi informasi dan komunikasi. Di sisi bahasa, teknologi informasi dan komunikasi yang sangat berkaitan dengan para pelajar, salah satunya adalah telepon genggam (Hand Phone/ HP). HP di ka- langan pelajar tidak asing lagi digunakan untuk berkomunikasi sehari-hari. Dalam pemanfaatannya, muncul bahasa dengan fitur linguistik yang sangat khas (bahasa daerah, bahasa Indonesia, dan bahasa Inggris).

Ditemukan data dari hasil observasi antara lain: rahajeng semeng $k k$ 'selamat pagi kakak', sya engsap kenken 'saya lupa 
bagaimana', tunggu dlu sya msh off 'tunggu dulu saya sedang tidak aktif', lya sbb sy dh ngantok $n i$ 'iya sebab saya sudah ngantuk ini', para siswa juga sering menggunakan bahasa gaul (prokem), pasaran, singkat, padat, dan jelas. Sebagai contoh penggunaan kata: lebay 'berlebihan', bagsel 'bagusseleh/ bagus cantik', knp lg? 'kenapa lagi?'. Terdapat pula gaya tulisan yang melipatgandakan huruf vokal maupun konsonan seperti: msihh, iyya, ayooooo, stresss, soryyy, okee, dan pleasee. Tulisan dengan menggantikan huruf lain dengan maksud sama, misalnya: cius? 'serius?', $C y$ 'saya', dan blz 'balas'. Ungkapan emosi sering dituliskan dengan lambang-lambang semiotik, berupa emoticon 'tanda rasa' antara lain: ;), (senyum), :D (tertawa), -_(sedih), :* (cium), (\{\}) (peluk), ('-') (senang), '-' (senang), $\left.<{ }^{\wedge} \wedge \wedge\right\rangle$ (bahagia).

Fenomena ini menarik untuk dicermati dalam arti mengumpulkan, memilih, memilah, mempelajari, dan mengetahui alasan mengapa fitur linguistik dan nonlinguistik yang ada, digandrungi oleh para siswa. Oleh karena itu, penelitian ini bertujuan untuk meneliti fitur linguistik dan non-linguistik penggunaan bahasa $S M S$ pada siswa SMPN 4 Mataram dan implikasinya terhadap pembelajaran bahasa Indonesia di sekolah.

\section{KONSEP DAN KERANGKA TEORI KONSEP}

\section{Konsep Fitur}

Brinton (2010), menjelaskan bahwa fitur adalah analisis semantis tentang komponen arti yang terkandung dalam suatu kata. Komponen tersebut terangkai untuk membentuk arti kata dengan cara yang berbeda-beda. Dengan demikian, fitur adalah bagian dari karakteristik semantis kata. Setiap kata dalam bahasa terdiri atas kumpulan fitur arti yang unik.

\section{Konsep Linguistik}

Istilah lingustics dalam bahasa Inggris berkaitan dengan kata language itu, seperti dalam bahasa Prancis istilah linguistique berkaitan dengan langage. Dalam bahasa Indonesia "linguistik" adalah nama bidang ilmu, dan kata sifatnya adalah "linguistis" atau "linguistik" (Verhaar, 1996: 3).

\section{Konsep Bahasa}

Bahasa adalah sistem tanda yang mengekspresikan gagasan, dan karenanya dapat dibandingkan dengan sistem tulisan, alfabet bagi para tuna-rungu dan tuna wicara, ritus simbolik, formulasi kesopanan, sinyal militer, dan lain-lain, tetapi bahasa merupakan sistem yang paling penting dari sistem-sistem lainnya Saussure (Danesi, 2012: 11).

\section{Konsep Implikasi}

Implikasi adalah keterlibatan atau keadaan terlibat (KBBI, 2002: 427).

\section{Konsep $S M S$}

Short Message Service disingkat 
$S M S$, merupakan sebuah layanan yang banyak diaplikasikan pada sistem komunikasi tanpa kabel, memungkinkan dilakukannya pengiriman pesan dalam bentuk alphanumeric antar terminal pelanggan antara terminal pelanggan dengan sistem eksternal seperti email, paging, voice mail, dan lain-lain. Isu $S M S$ pertama kali muncul di belahan Eropa pada sekitar tahun 1991 bersama sebuah teknologi komunikasi wireless yang saat ini cukup banyak penggunannya, yaitu Global System for Mobile Communication (GSM) (Rozidi, 2004: 1).

\section{KERANGKA TEORI}

Kadir (Uno, 2010: 107), peranan teknologi informasi dalam bidang pendidikan, akan melahirkan fitur-fitur baru dalam dunia pendidikan. Sistem pengajaran berbasis multimedia (teknologi yang melibatkan teks, gambar, suara, dan video) guru dapat menyajikan materi pelajaran dengan: lebih menarik, tidak monoton, dan memudahkan dalam penyampaian.

Penggunaan ujaran yang melibatkan kesesuaian peran pembicara-pendengar dalam suatu percakapan bukan hanya gambaran bagaimana menyampaikan makna dan gagasan, melainkan juga bukti interaksi sosial (Azies, 1996: 14). Semakin tinggi kelas sosial seseorang, semakin dekat varian linguistik mereka dengan varian bergengsi atau norma. Penutur bisa mengubah gaya bicara mereka untuk mendekati atau menjauhi varian yang bergengsi, ter- gantung pada tuntutan dan situasi yang sedang mereka hadapi (Thomas, 2007: 222).

Aneka proses linguistik pembentukan ekspresi bahasa gaul terdiri dari: Proses perubahan bunyi vokal, misalnya manakutahu $>$ meneketehe 'saya tidak tahu' lebay 'lebih' dan asoy 'asyik'; Proses perubahan konsonan seperti celamat < selamat, chayang < sayang, dan gicu < gitu; Proses penambahan bunyi, seperti bokap < bap(ak) : (bab + ok > bokap), gokil < gil(a) : $($ gil + ok $>$ gokil $)$; Proses penghilangan bunyi, misalnya $o$ 'on 'bloon, bodoh, tolol', bro 'brather, saudara' dan yola 'ayolah'; Proses perpindahan bunyi, misalnya pepsi 'pipis'(kencing), yipe 'piye' (bagaimana), yoi 'iyo' (ya); Proses pengembalikan bunyi, seperti elub-elub 'bule-bule' dan ogeb 'bego' (bodoh); Proses perulangan nini 'dingin' dan yayang 'sayang'; dan Perubahan ejaan, misalnya bohay < bohai 'bodi aduhai', skul 'sekolah', dan sakaw < sakau 'sakit karena putau' (Wijana, 2010: 25-47).

Pesan dalam surat elektronik acapkali menggunakan singkatan seperti $B T W$ (By the way) atau OTDH (On the other hand). Selain itu, emoticon juga sering dipakai. Yang dimaksud dengan emoticon adalah simbol-simbol yang mengungkapkan emosi. Beberapa contoh dapat dilihat di bawah ini: J senyum, L mengerutkan dahi, ;( mengedipkan mata, :-o terkejut, 8-o terguncang, :-s bingung, :-। ragu-ragu (Uno, 2010: 177).

Berdasarkan pendapat para ahli 
teknologi komunikasi dan bahasa tersebut di atas, dapat dikatakan bahwa teknologi informasi dan komunikasi merupakan sarana berupa peralatan elektronika, yang berkaitan dengan berita/kabar dengan menggunakan bahasa yang selalu mengikuti perkembangan zaman sebagai pengantar komunikasi yang sangat penting di dunia pendidikan dan kemasyarakatan, demi kebutuhan dan kenyamanan hidup.

\section{PEMBAHASAN}

Dalam bab ini disajikan hasil penelitian yang terdiri atas (1) deskripsi data fitur linguistik dan non-linguistik bahasa $S M S$ yang digunakan siswa kelas VIII 10 SMPN 4 Mataram tahun pelajaran 2014/ 2015; (2) analisis fitur linguistik dan nonlinguistik bahasa $S M S$ yang digunakan siswa kelas VIII 10 SMPN 4 Mataram tahun pelajaran 2014/2015; dan (3) analisis implikasi fitur linguistik dan non-linguistik penggunaan bahasa $S M S$ pada siswa kelas VIII 10 SMPN 4 Mataram tahun pelajaran 2014/ 2015 terhadap pembelajaran bahasa Indonesia di sekolah.

3.1 Deskripsi Data Fitur Linguistik dan Non-linguistik dalam Bahasa SMS

\begin{tabular}{|c|c|c|}
\hline No. & Fitur Linguistik & $\begin{array}{l}\text { Fitur Non- } \\
\text { linguistik }\end{array}$ \\
\hline 1 & Fonem: /h/liat, /i/krim, /h/tau, /s/dan /k/ajak, /u/about, /y/ia & \\
\hline 2 & $\begin{array}{l}\text { Morfem } \\
\text { 2.1 Morfem Bebas: Kpn, bru, } t d i, \text { di, brp, } n, \text { Gk, } t w \text {, sy, blum } \\
\text { 2.2 Morfem Dasar: blangin, geretak, ngangenin, mengamati } \\
\text { 2.3 Morfem Dasar Terikat: berhenti, temuin, omongin, } \\
\text { 2.4 Morfem Unik: Ngebolak balik } \\
\text { 2.5 Klitik: Klitik -mu: klompokmu. Klitik-nya: bukunya }\end{array}$ & \\
\hline 3 & Leksikon: Di, sruh, blajar, km, ini, bikin, sya, kaget, ajk, tia, hri & \\
\hline 4 & Frase: Ampe kadar air, Ndk ada puls jga sya, Sabtu kayaknya & \\
\hline 5 & $\begin{array}{l}\text { Kalimat } \\
\text { 5.1 Kalimat Aktif: Say mw nyuci spatu dlu bye } \\
\text { 5.2 Kalimat Pasif: Hehehee. Bku sy dibwak dyu arik tu } \\
\text { 5.3 Kalimat Tunggal: Sya diktein dh ya } \\
\text { 5.4 Kalimat Berita: Bsok di suruh bawa hp sma omang } \\
\text { 5.5 Kalimat Perintah: Emi, bsok ajrin sy pr mtk itu ya pliss } \\
\text { 5.6 Kalimat Tanya: kpn kta k taman lg nyek? } \\
\text { 5.7 Kalimat Langsung: Bagi siswa-siswi smpn } 4 \text { mtr, khususnya kelas VIII, } 10 \text { besok } \\
\text { bwak HP + SULING! Don't forget! } \\
\text { 5.8 Kalimat Tidak Langsung: Weee,bwat sluruh klas } 8.10 \text { bsok hari rabu kita } \\
\text { ulangan matematika ya, tentang relasi dan fungsi itu katanya pak ainul!! } \\
\text { 5.9 Kalimat Majemuk } \\
\text { 5.9.1 Kalimat Majemuk Setara: Ips kykx yg mengamati tmbuhan, trus b.ix yg } \\
\text { transitif dn intransitif! } \\
\text { 5.9.2 Kalimat Majemuk Bertingkat: Jebol atep mamik sya gra” sya....sumpah } \\
\text { malunya sya. }\end{array}$ & \\
\hline 6 & $\begin{array}{l}\text { Pola Bahasa } \boldsymbol{S M S} \text { (tanpa salam pembuka/ penutup). } \\
\text { Pak mntk tlng sruh pak ile jmpt di dyu arix. }\end{array}$ & \\
\hline
\end{tabular}




\begin{tabular}{|c|c|c|}
\hline 7. & 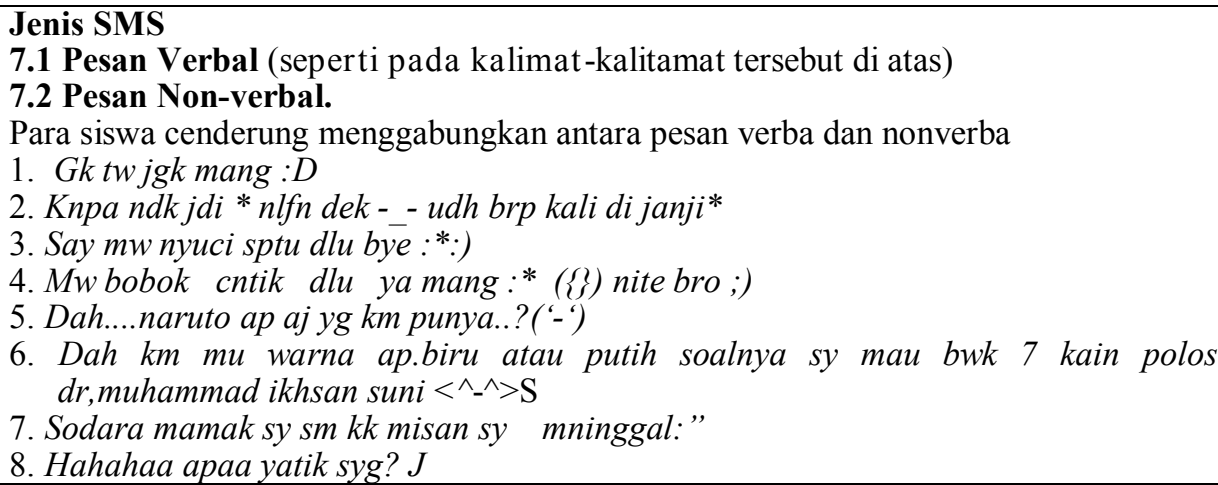 & 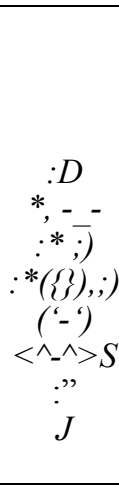 \\
\hline 8. & $\begin{array}{l}\text { Fungsi SMS } \\
\text { 8.1 Fungsi Informatif: Cy kena air hujan tdi mngkkx cy sedikit demam dan pus- } \\
\text { ing } \\
\text { 8.2 Fungsi Direktif: Inget bwak hp blngin yang lain jg } \\
\text { 8.3 Fungsi Ekspresif: Iihh pokoknya sya gk suka sma sifatnya nov nov } \\
\text { yang skrang } \\
\text { 8.4 Fungsi Komisif: Jangan ngambul besok sy beliin cilok } \\
\text { 8.5 Fungsi Fatis: Say mw nyuci sptu dlu bye:*;) } \\
\text { 8.6 Fungsi Poetik: bagsel (bagusseleh), Olga (olah raga) }\end{array}$ & $\left.:^{*} ;\right)$ \\
\hline 9. & $\begin{array}{l}\text { Makna } \mathbf{S M S} \\
\text { 9.1 Makna Leksikal: Mang, Ada, Orang, Sholat, D, Skolah, Ad } \\
\text { 9.2 Makna Gramatikal: pnggguna, dimarah,jawabannya, } \\
\text { 9.3 Makna Kontekstual: Ngangenin, gombal, Bisa } \\
\text { 9.4 Makna Idiomatikal: Meninggal }\end{array}$ & \\
\hline
\end{tabular}

Fitur Linguistik Bahasa Sms yang Digunakan Siswa Kelas Viii 10 Smpn 4 Mataram Tahun Pelajaran 2014/ 2015 Grafem

Fonem adalah satuan bunyi terkecil yang mampu menunjukkan kontras makna yang memungkinkan pembicara sebuah bahasa membedakan dan mengidentifikasi kata-kata.

Udah sya krim 2.

'Sudah saya kirim 2.'

'Saya sudah mengirim 2.'

\section{Morfem}

Morfem adalah satuan gramatikal terkecil yang dapat membedakan makna dan atau mempunyai makna serta tidak dapat dibagi atas bagian bermakna yang lebih kecil. Adapun jenis-jenis morfem antara lain Morfem Bebas, yaitu morfem yang secara potensial dapat berdiri sendiri tanpa terkait dengan morfem lain dalam suatu kalimat.

Kpn, Bru, tdi, di, brp, n, Gk, tw, sy, blum, ctet.

'kapan, baru, tadi, di, berapa, dan, tidak, tahu, saya, belum, catat.'

'kapan, baru, tadi, di, berapa, dan, tidak, tahu, saya, belum, mencatat.'

Morfem Dasar adalah morfem morfem yang dapat diperluas melalui proses morfologi dengan cara pengimbuhan afiks.

ngngenin

'ngangenin'

'membuat kangen'

Di samping itu, terdapat pula jenis Morfem Dasar Terikat, yakni morfem dasar yang harus digabung dengan afiks atau morfem lain untuk dapat digunakan dalam percakapan.

berhenti

'berhenti' 
'tidak meneruskan lagi'

Jenis morfem lain adalah Morfem Unik, yakni morfem terikat yang hanya mampu berkombinasi dengan satuan tertentu.

\section{ngebolak balek}

'ngebolak balik'

'membolak balik'

Terdapat pula Klitik, yaitu morfem yang selalu muncul dalam keadaan terikat dengan bentuk lain, tetapi keterikatannya dapat dipisah atau diganti dengan morfem yang lain. Klitik ditulis dirangkai dengan kata yang mendahului atau mengikutinya. Bentuk klitik antara lain: $\{k u-\},\{k a u-\},\{-$ $n y a\}$, dan $\{-m u\}$.

Contoh klitik $\{-m u\}$

klompokmu

'kelompokmu'

'kelompok kamu/ kelompok anda'

Contoh klitik $\{-n y a\}$

bukunya

'bukunya'

'buku dia (pronomina pesona/ pronomina benda yang menyatakan milik)'

\section{Leksikon}

Leksikon adalah perbendaharaan kata atau koleksi leksem pada suatu bahasa yang memuat informasi tentang makna dan pemakaian kata dalam bahasa.

$d i$

'di'

'di artinya prefiks pembentuk verba dikenai suatu tindakan'

\section{Frasa}

Frasa adalah gabungan dua kata atau lebih yang bersifat non-predikatif atau tidak memiliki predikat dalam strukturnya. Frasa merupakan satuan linguistik yang lebih besar dari kata dan lebih kecil dari klausa dan kalimat.

Ndk ada pulsa jga sya

'Tidak ada pulsa juga saya'

'Tidak ada pulsa juga saya'

\section{Kalimat}

Kalimat adalah satuan bahasa yang terdiri atas subjek, predikat, dan objek.

Dalam BI, dikenal Kalimat Aktif, yakni kalimat yang subjeknya melakukan perbuatan dan mempunyai predikat berupa kata kerja berawalan $\{m e-\}$ atau $\{b e r\}$.

Say mw nyuci spatu dlu bye 'Saya mau nyuci sepatu dulu da' 'Saya mau mencuci sepatu dulu da'.

Adapun Kalimat Pasif adalah kalimat yang subjeknya dikenai pekerjaan sebagai tujuan dari perbuatan dan memiliki predikat berupa kata kerja berawalan $\{d i-\}$.

Hehehee. Bku sy dibwakdyu ariktu 'Hehehee, buku saya dibawa Dayu Arik itu'

'Hehehe, buku saya dibawa Dayu Ari itu' Jenis yang lain adalah Kalimat Tunggal, yakni kalimat yang hanya terdiri dari inti kalimat atau satu klausa.

Sya dktein dh ya

'Saya diktekan sudah ya'

'Saya sebutkan satu-persatu ya'

Selanjutnya, Kalimat Berita, yakni 
kalimat yang isinya memberitahukan sesuatu.

Bsok di suruh bawa hp sma omang 'Besok disuruh bawa HP sama Komang' 'Besok disuruh bawa Hand Phone oleh Komang'

Di samping itu, dalam BI dikenal Kalimat Perintah,yaitu kalimat yang bermakna perintah atau larangan kepada orang lain untuk melakukan sesuatu. Dalam bahasa tulis, lazimnya diakhiri dengan tanda seru (!).

Emi, bsok ajrin sy prmtk itu ya pliss

'Emi, besok ajarin saya PR matematika itu ya mohon!'

'Emi, besok ajarkan saya PR matematika itu ya, tolong!'

Pola kalimat yang lain adalah Kalimat Tanya, yakni kalimat yang bermakna pertanyaan yang isinya menanyakan sesuatu atau seseorang sehingga diperoleh jawaban tentang suatu masalah. Dalam bahasa tulis lazimnya diakhiri dengan tanda tanya (?).

\section{kpn kta \\ $k$ taman lg nyek?}

'Kapan kita ke taman lagi Nyek?'

'Kapan kita pergi ke taman lagi, Nyek?'

Adapun kemudian jenis penggunaan kalimat dalam BI dikenal Kalimat Langsung, yaitu kalimat yang secara cermat menirukan ucapan orang atau memberitakan bagaimana ucapan dari orang lain (orang ketiga). Kalimat langsung lazimnya ditandai dengan tanda petik ( “.........”).

Bagi siswa-siswi smpn $4 \mathrm{mtr}$,

khu- susnya kelas VIII. 10 besok bwak HP

'Bagi siswa-siswi SMPN 4 mataram, khususnya kelas VIII 10 besok bawa $H P$ 'Bagi siswa-siswi SMPN 4 mataram, khususnya kelas VIII 10 besok bawa $H P$ + SULING! Don't forget! dan suling! Don't forget!' dan suling. Don 't forget (jangan lupa)!'

Sebaliknya, Kalimat Tidak Langsung, adalah kalimat yang menirukan kembali ucapan atau perkataan orang lain.

Weee, bwat sluruh klas 8. 10 bsok hari rabu kita ulangan matematika

'Weee, buat seluruh kelas VIII 10 besok hari Rabu kita ulangan matematika 'Weee, "Kepada seluruh kelas VIII 10 besok hari Rabu ulangan matematika, $y a$, tentang relasi dan fungsi itu katanya pak ainul!!

ya, tentang relasi dan fungsi itu katanya pak Ainul'

ya, tentang relasi dan fungsi" kata pak Ainul'

Selain kalimat tersebut di atas, dalam BI juga terdapat Kalimat Majemuk, yakni kalimat yang mempunyai dua pola kalimat atau lebih yang dipadukan menjadi satu. Ada berbagai Kalimat Majemuk, diantaranya Kalimat Majemuk Setara adalah kalimat yang terdiri dari beberapa klausa yang koordinatif.

Ips kykx yg mengamati tmbuhan, trus $b \quad i x \quad y g$

'IPS kayaknya yang mengamati tumbuhan, terus bahasa Indonesianya yang

'IPS sepertinya yang mengamati tumbuhan, 
terus bahasa Indonesianya yang

transitif dn intransitif!

transitif dan intransitif!'

transitif dan intransitif!'

dan Kalimat Majemuk Bertingkat, yakni kalimat yang terdiri dari beberapa klausa yang kedudukannya tidak setara/ sederajat atau subordinatif.

Jebol atep mamik sya gra” sya....sumpah malunya sya.

'Jebol atap bapak saya gara-gara saya....sumpah malunya sya.'

'Lobang atap bapak saya gara-gara saya, sungguh saya malu.'

\section{Fitur Non-linguistik dalam Bahasa SMS}

Bentuk-bentuk nonlinguistik dalam bahasa SMS para siswa SMPN 4 berupa emoticon (tanda rasa) antara lain: ;) (senyum), :D (tertawa), -_- (sedih), :* (cium), ( \{\} ) (peluk), ('-') atau '-' (senang), dan $\left\langle\wedge_{-} \wedge>\right.$ S (bahagia).

Pengelompokan Fitur Linguistik dan Non-Linguistik Dalam Bahasa Sms Berdasarkaan Pola Bahasa, Jenis, Fungsi, dan Makna

Pola bahasa $S M S$ para siswa pada umumnya tidak menggunakan salam pembuka maupun penutup (assalamualaikum, aslm.wr.wb, aslm, selamat pagi, slmt sore, atau wassalam).

Pak mntk tlng sruh pakilejmpt di dyu arix..

'Pak minta tolong suruh pak Ile jemput di Ida Ayu Arinya.'

'Pak minta tolong, suruh pak Ile jemput di rumah Dayu Ari.'
Jenis Sms Para Siswa Berupa Pesan Verbal dan Non-Verbal

Pesan Verbal adalah pesan yang penyampaiannya menggunakan kata-kata, dan dapat dipahami oleh penerima. Bagi pakar semiotika, teks yang menghantarkan pesan verbal secara semiotik tidak berbeda dengan teks nonverbal. Dalam semiotika, verbalitas hanya dianggap sebagai salah satu modalitas semiotik yang digunakan manusia untuk membuat pesan (Danesi, 2012: 107-108). Pesan verba bisa berupa kalimat aktif, kalimat pasif, kalimat tunggal, kalimat berita, kalimat perintah, kalimat tanya, kalimat langsung, kalimat tidak langsung, dan kalimat majemuk (seperti yang sudah dijelaskan di atas). Sebaliknya Pesan Non-verbal adalah jenis pesan yang penyampaiannya tidak menggunakan katakata secara langsung, dapat dipahami isinya berdasarkan gerak-gerik, tingkah laku, mimik wajah, atau ekspresi muka. Bahasa SMS yang digunakan para siswa cenderung menggabungkan antara pesan verbal dan nonverbal yang berupa emoticon (tanda rasa) antara lain: ;) (senyum), $: D$ (tertawa), -_ (sedih), :* (cium), $(\{\})$ (peluk), ('-') atau '-' (senang), dan $\left\langle\wedge \_\wedge>S\right.$ (bahagia). Hal ini untuk menegaskan tentang pesan yang disampaikan.

Fungsi bahasa $S M S$ antara lain sebagai Fungsi Informatif, yaitu fungsi bahasa yang digunakan untuk memberitahukan sesuatu.

Cy kena air hujan tdi mngkkx cy sedikit demam dan pusing

'Saya kena air hujan tadi makanya saya 
sedikit demam dan pusing.'

'Saya terkena air hujan tadi, maka dari itu saya agak demam dan pusing.'

Selain itu sebagai Fungsi Direktif, yakni fungsi bahasa yang digunakan untuk menyuruh, mengajak atau menyarankan lawan bicara melakukan sesuatu.

Inget bwak hp blngin yang lain jg

'Ingat bawa $H P$ bilangin yang lain juga' 'Ingat bawa $H P$ beri tahu yang lain juga!'

Fungsi bahasa SMS yang lain sebagai Fungsi Ekspresif, yaitu fungsi bahasa yang digunakan untuk mengekspresikan atau mengungkapkan berbagai perasaan.

Iihh pokoknya sya gk suka sma sifatnya nov nov yang skrang

'Ih pokoknya saya tidak suka sama sifatnya Novi yang sekarang'

'Ih, pokoknya saya tidak suka dengan si-

fat Novi yang sekarang'

Di samping itu terdapat Fungsi Komisif, yakni fungsi bahasa yang digunakan untuk membuat perjanjian atau sumpah bahwa seseorang (penutur) akan, tidak, atau tidak akan melakukan sesuatu.

Jangan ngambul besoksy beliin

cilok

'Jangan ngambul besok saya be-

likan cilok'

'Jangan ngambek/ marah besok saya belikan cilok'

Sedangkan Fungsi Fatis adalah fungsi bahasa yang digunakan untuk mengawali komunikasi atau mengakhiri komunikasi dengan lawan tutur.

Say mw nyuci sptu dlu bye:*;)
'Saya mau nyuci sepatu dulu bye (tanda rasa: cium dan senyum)'

'Saya mau mencuci sepatu dulu da (tanda rasa: cium dan senyum)'

Selain fungsi-fungsi bahasa tersebut di atas, terdapat pula Fungsi Poetik, yakni fungsi bahasa yang berkaitan dengan peran bahasa untuk mengungkapkan keindahan atau membentuk tuturan yang indah; satuan ekspresi ringkas, yang menimbulkan keindahan tertentu bila diucapkan, dan tidak tergantikan oleh satuan lingual lainnya (Wijana, 2010: 112-118). Bentuk bagsel (bagusseleh) artinya bagus cantik; bagus sekali atau sangat bagus'. Bentuk Olga dalam hal ini bukan berarti nama 'artis papan atas yang telah meninggal (almarhum Olga Syahputra)', melainkan satuan ekspresi ringkas dari 'olah raga (seragam untuk olah raga)'.

\section{Makna SMS}

Makna adalah maksud yang terkandung dalam suatu kata atau kalimat. Di dalam BI terdapat Makna Leksikal, yaitu makna yang secara langsung dimiliki oleh setiap bentuk dasar. Bentuk Ada, maknanya 'hadir; telah sedia'. Dalam bahasa SMS sering dijumpai bentuk ada menjadi ad. selain itu terdapat pula Makna Gramatikal, yakni makna yang terjadi sebagai hasil proses secara gramtikal. Bentuk jawabannya, maknanya 'jawaban dari'. Berasal dari morfem dasar jawab, mendapat digabung dengan sufiks $\{-n y a\}$. Jenis makna yang lain Makna Kontekstual, adalah 
makna penggunaan sebuah kata (gabungan kata) dalam keseluruhan kalimat (ujaran) pada konteks situasi tertentu. Bentuk gombal maknanya 'bohong; omong kosong; rayuan', bukan berarti 'kain yang sudah tua (sobek-sobek)'. Bentuk gombal digunakan untuk mengugkapkan rasa tidak percaya, karana penutur atau lawan tutur menyampaikan suatu hal yang tidak nyata. Selanjutnya dikenal pula Makna Idiomatikal, yaitu makna yang dalam unsur-unsur pembentukannya tidak terkait dengan makna leksikal maupun makna gramatikal. Bentuk Meninggal maknanya 'wafat' atau 'mati', bukan 'melakukan kegiatan tinggal'.

Implikasi Fitur Linguistik dan NonLinguistik Penggunaan Bahasa Sms Pada Siswa Kelas Viii 10 Smpn 4 Mataram Tahun Pelajaran 2014/ 2015 Terhadap Pembelajaran Bahasa Indonesia di Sekolah

Berdasarkan hasil pelaksanaan pembelajaran yang dilakukan pada tanggal 20 April 2015 dan 11 Mei 2015 terkait dengan mata pelajaran Bahasa Indonesia dengan: Standar Kompetensi (SK): Mengungkapkan informasi dalam bentuk rangkuman teks berita; Kompetensi Dasar (KD): Menulis teks berita secara singkat, padat, dan jelas; Tujuan Pembelajaran: Siswa mampu menulis teks berita secara singkat, padat, dan jelas; dan Materi Pembelajaran: Penulisan teks berita, ternyata para siswa menggunakan bahasa baku pada saat mengerjakan tugas sekolah baik dari segi fonem, morfem, leksikon, frasa, maupun kalimat.

Fitur linguistik dan non-linguistik penggunaan bahasa $S M S$ para siswa dan pembelajaran bahasa Indonesia di sekolah tentang penulisan teks berita sama-sama menggunakan bahasa yang singkat, padat, dan jelas, namun para siswa mampu membedakan pemakaian bahasa Indonesia yang baku untuk kepentingan formal dan bahasa gaul atau bahasa sosialita untuk kepentingan kemanusiaan. Fitur linguistik dan non-linguistik penggunaan bahasa SMS pada siswa tidak berpengaruh langsung kepada respon siswa. Secara natural mereka paham dengan seting, topik, pertanyaan, dan setiap wacana dalam bahasa formal maupun informal.

\section{SIMPULAN}

Berdasarkan hasil penelitian dan pembahasan di atas, dapat disimpulkan sebagai berikut. (1) Fitur linguistik bahasa SMS yang digunakan siswa antara lain berupa: fonem, morfem, leksikon, frasa, dan kalimat. Pola bahasa SMS tidak menggunakan salam pembuka maupun penutup, Jenis $S M S$ berupa pesan verbal dan non-verbal, fungsi $S M S$ sebagai fungsi: informatif, direktif, ekspresif, komisif, fatis, poetik, makna SMS sebagai makna: leksikal, gramatikal, kontekstual, dan idiomatikal. Fitur non-linguistik bahasa SMS yang digunakan siswa berupa emoticon (tanda rasa), antara lain berupa: : ;) (senyum), :D (tertawa), -_- (sedih), :* (cium), (\{\}) (peluk), ('-') atau '-' (senang), 
dan $\left\langle\wedge \_\wedge>S\right.$ (bahagia). Hal ini untuk menegaskan tentang pesan yang disampaikan; (2) Implikasi fitur linguistik dan nonlinguistik penggunaan bahasa $S M S$ para siswa terhadap pembelajaran bahasa Indonesia di sekolah. Bahasa SMS dan pembelajaran tentang penulisan teks berita keduanya menggunakan bahasa yang singkat, padat, dan jelas, namun para siswa mampu membedakan pemakaian bahasa Indonesia yang baku untuk kepentingan formal dan bahasa gaul atau bahasa sosialita untuk kepentingan kemanusiaan. Fitur linguistik dan non-linguistik penggunaan bahasa $S M S$ pada siswa tidak berpengaruh langsung kepada respon siswa. Secara natural mereka paham dengan seting, topik, pertanyaan, dan setiap wacana dalam bahasa formal maupun informal.

\section{DAFTAR PUSTAKA}

Azies, Furqanul dan A. Chaedar Alwasilah. 1996. Pengajaran Bahasa Komunikatif. Bandung: PT Remaja Rosdakarya Bandung.

Danesi, Marcel. 2012. Pesan, Tanda, dan Makna. Yogyakarta: Jalasutra.

Rosidi, Romzi Imron. 2004. Membuat Sendiri SMS Gateway Berbasis Protokol SMPP. Yogyakarta: Andi.

Thomas, Linda dan Shan wareing. 2007. Bahasa, Masyarakat \& Kekuasaan. Yogyakarta: Pustaka Pelajar.

Uno, B, Hamzah dan Nina Lamatenggo. 2010. Teknologi Komunikasi \& Informasi Pembelajaran. Jakarta: PT Bumi Aksara.

Verhaar. 1996. Asas-asas Linguistik Umum. Yogyakarta: Gadjah Mada university Press.

Wijana, I Dewa Putu 2010. Bahasa Gaul Remaja Indonesia. Malang: Aditya Media Publising.

http://saynotogaptek.blogspot.com/2012/03/apa -itu-fitur-dalam-istilah teknologi.html 